\title{
Intramural Research Award
}

National Cancer Institute

\section{Source}

National Cancer Institute. Intramural Research Award. NCI Thesaurus. Code C19333.

The DCEG Intramural Research Award (IRA) is a new competitive funding mechanism to encourage exciting interdisciplinary projects that are innovative and cross the usual organizational boundaries. IRA recipients are recognized for their creative ideas and scientific skills in advancing the goals of the National Cancer Institute. Features of the IRA program include the following: Only Principal Investigators (PIs) are eligible to receive an IRA, although scientific collaborators may include non-PIs; Priority will be given to collaborative projects that are innovative and have potential for significant scientific or public health impact, including development of resources to facilitate population-based research (e.g., creation of a novel database or research model). Starting with FY1999 Pre-and Post-doctoral fellows became eligible for DCEG Intramural Research Awards. 